heterogeneous due to stochastic effects in gene expression. Many theoretical studies on gene expression fluctuation approximate the effect of growth and cell division simply assuming that protein decay rate is the sum of degradation and dilution rates. The global effects of macro parameters, such as growth and cell division, on intracellular gene expression fluctuation, however, remain largely unknown. To find the relation between growth and fluctuation in Escherichia coli, we developed a new microfluidic device that allows rigorous environmental control and tracking of a large number of individual cells for hundreds of generations. We thereby measured an inheritable character, defined here as a decay in the auto-correlation function of gene expression level, under several growth conditions. As a result, it has been revealed that the decay of autocorrelation function is slow; the correlation decreases only to $\sim 0.8$ per average doubling time. We also found that a decrease in growth rate increases the decaytime of the auto-correlation function of expression fluctuation in single cells. Such "growth rate-dependent memory preservation" may underlie the universality of cellular phenotypic adaptation to various environmental changes.

\section{J1536 大腸菌における表現型遺伝性と抗生物質への適応の一細胞計測}

Single-Cell Level Observation of Phenotypic Heredity and Adaptation to Antibiotic in Escherichia Coli

Takashi Nozoe ${ }^{1}$, Reiko Okura ${ }^{1}$, Yuichi Wakamoto ${ }^{1,2}\left({ }^{1}\right.$ Grad. Sch. Arts and Sci., Univ. Tokyo, ${ }^{2}$ JST PREST)

In a clonal cell population, each cell has different individuality, which might be inherited to next generation. In fact, it is known that not only dose protein copy number fluctuate temporally and from cell to cell, but also its autocorrelation decays slowly over a few generations in Escherichia coli. In this sense, the gene expression exhibits "primitive heredity", which may lead to phenotypic adaptation in a lethal environment, such as bacterial persistence, when the copy number of some protein in each cell strongly affects its survival. In order to clarify such role of stochastic gene expression in the context of adaptation, the authors constructed an $E$. coli strain that expresses the fusion of antibiotic resistant and fluorescent proteins from an inducible promoter, and observed the strain in two ways. At first, we confirmed that the survivability of the strain in antibiotic exposure was higher than that of the wild type and correlated with the induction levels. Next, we simultaneously observed the growth and the fluorescent level of the strain using a microfluidic device, and successfully detected a small number of survivors among a clonal cell population that proliferated after the withdrawal of the antibiotic. To directly verify the role of "primitive heredity" experimentally, we also constructed a modified strain that expresses destabilized fusion proteins and confirmed that its autocorrelation of protein copy number decays faster. We will discuss the usability of the singlecell level observation system described above.

\section{$2 J 1548$ 心觔を模倣した自励振動ゲルによるソフトロボットの創製}

\section{Devel of novel autonomous doft robot}

Yusuke Hara ${ }^{1}$, Shingo Maeda ${ }^{2}$, Shuji Hashimoto ${ }^{3}\left({ }^{1}\right.$ AIST, ${ }^{2}$ Shibaura Univ., ${ }^{3}$ Waseda Univ.)

We introduce autonomous gel actuators driven by chemical energy. The polymer gels prepared here have cyclic chemical reaction networks. With a cyclic reaction, the polymer gels generate periodical motion. The periodic motion of the gel is produced by the chemical energy of the oscillatory Belouzov-Zhabotinsky (BZ) reaction. We have succeeded in making synthetic polymer gel move autonomously like a living organism. This experimental fact represents the great possibility of the soft robot.

\section{J1612 V 字型電極アレイを用いた誘電泳動力による微粒子の連続的濃縮分}

\section{離}

Continuous Concentration and Separation of Microparticles Using Dielectrophoretic Force in a V-Shaped Electrode Array Masahito Hayashi ${ }^{1}$, Hyonchol Kim ${ }^{1}$, Hideyuki Terazono ${ }^{1}$, Akihiro Hattori ${ }^{1}$ Kenji Yasuda ${ }^{1,2}$ ( ${ }^{1}$ Yasuda "On-chip Molecular Cell Phenomics" Project, KAST, ${ }^{2}$ Inst. Biomat. Bioeng., Tokyo Med. Dent. Univ.)

We have proposed and developed the novel principle of a $\mathrm{V}$-shaped electrode array in a microfluidic pathway for continuous-concentration and -separation of particles by dielectrophoretic (DEP) force. The advantage of V-shape microelectrode arrays with a microfluidic flow for cell separation is that whole particles are concentrated into the center of a micropathway independent of the difference in their dielectric constants in the $\mathrm{X}-\mathrm{Y}$ plane, while the particles are split between the top or bottom of the micropathway in the Z-axis direction depending on the differences in their dielectric constants and the applied $\mathrm{AC}$ frequency. After the application of a sinusoidal $\mathrm{AC}$ voltage of $1 \mathrm{MHz}$ and $20 \mathrm{Vpp}$, both polystyrene spheres and Bacillus subtilis spores were concentrated at the tip of the V-shaped electrode at the center of microfluidic flow in the X-Y plane independent of their dielectric constant differences. They were also split into two directions in the Z-axis, i.e., polystyrene spheres rose to the top, and spores went down to the bottom depending on their dielectric constant differences and were successfully separated in two layered downstreams. The results indicate the potential of $\mathrm{V}$-shaped electrode arrays for simple continuous purification of mixed particles depending on their dielectric constants.

\section{$2 J 1624$ 非常時の科学コミュニケーション : 基礎科学者に何ができるか}

Science Communication by Basic Scientists in Crisis Settings

Senkei Umehara ${ }^{1,2}$ ( ${ }^{1}$ Dept. Sci. Soc., Sci. Commun. Hq., JST, ${ }^{2}$ Grad. Art. Sci., Univ. Tokyo)

The Great East Japan Earthquake and the following nuclear and radiation accidents represented a milestone in the history of science communication. Trust in science and the scientific community has been challenged; it is not simply due to the insufficient quality and quantity of published data but rather to the confusion about the way of communicating those data as evidence-based, "interpreted" messages at the right timing to the right audience by the right spokespeople. In such crisis settings, knowledge and the capacity of basic scientists tend to be limited and therefore, their roles continue to be unclear. To discuss the roles of scientists in science communication, first the talk will introduce feedback from two past sessions. One is about barriers and motivations for their participation in science communication activities, which was held at the Biophysical Society of Japan Annual Meeting in 2010; the other is about how and to what extent such activities can be carried out by scientists themselves, which was held as a featured session at Science Agora 2010. The talk will then move on to open-ended discussion, mainly focusing on how to maximize the contribution of basic scientists to society at large, and how trust in science can be (re-)gained through improved communication.

This talk is intended for an interactive case study among the audience, with the presenter providing some noteworthy pieces of information. Open-minded scientists at any career stage will be welcomed.

\section{J1636 Fabrication of gold nanoparticles in cells by laser-induced} photoreduction

Kentaro Mochizuki ${ }^{1}$, Nicholas Isaac Smith ${ }^{2}$ ( ${ }^{1}$ AppliedPhysics, GradSch, Univ. Osaka, ${ }^{2}$ Biophotonics lab, IFReC, Univ. Osaka)

Noble metal nanoparticles have attracted a great deal of attention in optical and medical fields due to their unique optical properties, notably the Localized Surface Plasmon Resonance (LSPR). When introduced in live cells, metal nanoparticles are known to retain this unique property. The electromagnetic field induced around nanoparticles by LSPR enables Surface Enhanced Raman Scattering (SERS) of chemical constituents in cells and photothermal therapy of cancer cells. Accordingly, different techniques to introduce metal nanoparticles into cells were investigated in recent years.

In our group, one unique technique was investigated involving the fabrication of gold nanoparticles inside cells by laser-induced photoreduction. HeLa cells were irradiated with $532 \mathrm{~nm} \mathrm{CW}$ laser after incubation in gold ion solution, resulting in the fabrication of gold nanoparticles in the desired position. After the fabrication process, the appearance of black points in laser-irradiated areas in cells was confirmed in the bright field image. These black points were due to the laser-induced reaction of gold ions since no changes were observed in cells without gold ions under the same laser irradiation process. Indeed, the existence of photoreduced gold nanoparticles in cells was shown by Transmission Electron Microscopy and Energy Dispersive X-ray analysis. Those gold nanoparticles had $5 \sim 15 \mathrm{~nm}$ diameter and appeared close to each other but not touching inside the cells.

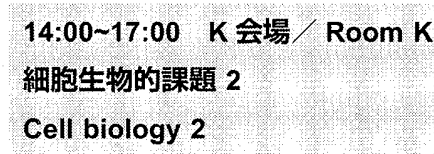

2K1412 活性化後に起こる Ga2 と cAMP 受容体間相互作用の検証

Novel mechanism of interaction between active $G$ protein alpha subunit and GPCR 